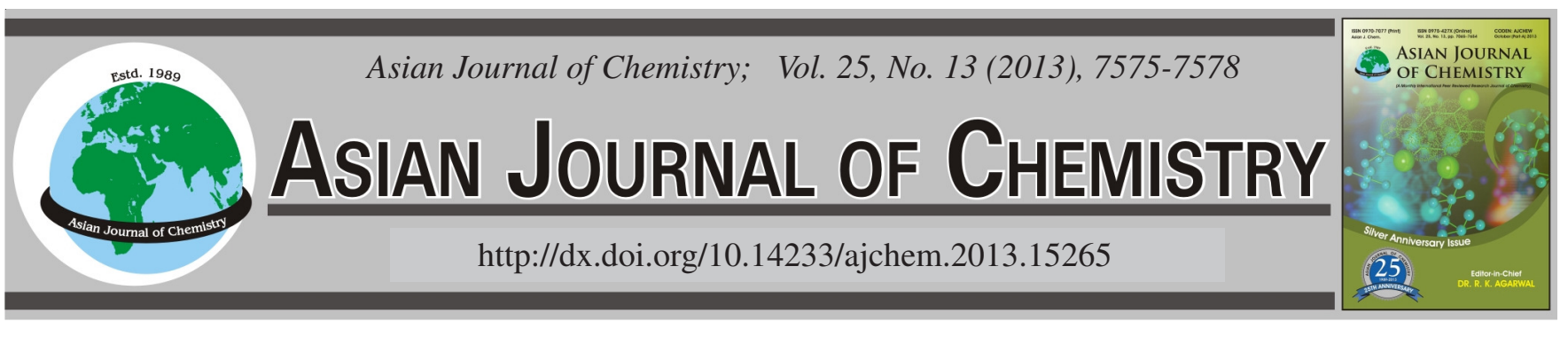

\title{
Spectrophotometric Determination of Flavonoids Content in Leaves of Fagopyrum cymosum Complex
}

\author{
Guang $\mathrm{Li}^{1}$, Shuang Yu ${ }^{2}$, Yong-Hong Zhou ${ }^{1, *}$ and Qing-Fu Chen ${ }^{1, *}$
}

${ }^{1}$ Triticeae Research Institute, Sichuan Agricultural University, No. 211 HuiminLu, Chengdu 611130, P.R. China

${ }^{2}$ Research Center of Buckwheat Industry Technology/Institute of Plant Genetic and Breeding, School of Life Sciences, Guizhou Normal University, No. 116 BaoshanBeiLu, Guiyang 550001, Guizhou Province, P.R. China

*Corresponding authors: Tel: +86 28 82650350; E-mail: zhouyhdavid@126.com; cqf1966@163.com

(Received: 4 February 2013;

Accepted: 1 July 2013)

AJC-13755

\begin{abstract}
Fagopyrum cymosum complex is a traditional Chinese medicinal herb, which is rich in flavonoids and has great medicinal value. In this work, the optimum extraction conditions of flavonoids from $F$. cymosum complex leaves were investigated by orthogonal design. Six methodological factors (including alcohol concentration, material-liquid ratio, reaction temperature, distilled time, extraction times and ultrasonic power) were studied using an L18 $\left(3^{7}\right)$ orthogonal test table. The results showed that the effects of each factor on the extraction of flavonoids in order were as follows: alcohol concentration $>$ materials-liquid ratio $>$ ultrasonic power $>$ extraction times $>$ distilled time $>$ reaction temperature, the effect of alcohol concentration on extraction was extremely significant, while the effect of other factors was not. The highest yield was obtained when alcohol concentration, liquid material ratio, ultrasonic power, extraction times, distillation time, reaction temperature were $60 \%, 1: 20(\mathrm{w} / \mathrm{v}), 70 \%(175 \mathrm{w})$, three times, $20 \mathrm{~min}$ and $40{ }^{\circ} \mathrm{C}$, respectively. And the crude extract of flavonoids was determined using four kinds of spectrophotometric methods, The results show that the method D $\left(\mathrm{HAC}^{\mathrm{AlCl}} \mathrm{l}_{3}\right.$ spectrophotometric method) was the best. It's a simple, accurate and precise method for the determination of flavonoids content in leaves of $F$. cymosum complex.
\end{abstract}

Key Words: Spectrophotometric method, Flavonoids, Fagopyrum cymosum complex, Orthogonal design, Polyphenol.

\section{INTRODUCTION}

Flavonoids are one of the largest (> 6000 identified) and most widely distributed groups of secondary plant metabo$\operatorname{lites}^{1}$ and are found in practically all photosynthesizing plants. Flavonoids are polyphenolic compounds showing a common basic C6-C3-C6 skeleton structure consisting of a heterocyclic pyran or pyrone ring flanked by a benzene ring on each $\operatorname{side}^{2}$. Flavonoids compounds are known to be responsible for antioxidant $^{3}$, anticancer ${ }^{4}$, antiinflammatory ${ }^{5,6}$, hepatoprotective potential $^{7}$, antithrombotic ${ }^{8}$ and antibacterial activity ${ }^{9}$. The $F$. cymosum complex belongs to polygonaceae, is a perennial dicotyledonous plant. It is a group of wild perennial buckwheat which includes the diploid species $F$. megaspartanium Q. F. Chen and F. pilus Q. F. Chen as well as the allotetraploid species F. cymosum (Trev.) Meisn ${ }^{10-12}$. It's a traditional Chinese medicinal herb. It is rich in flavonoids and has great medicinal value.

In this work, the optimum extraction conditions of flavonoids from $F$. cymosum complex leaves are investigated by the orthogonal test design, which is a highly efficient, fast and economic experimental design method. UV-visible spectro- photometric, which is commonly measurement methods of flavonoids, has the advantages of precision, accuracy, lowcost and easy handling. However, the spectrophotometers usually used at present are not necessarily to be the best.Thus it is necessary to develop a new determination method to determine the content of flavonoids. So four methods commonly used in laboratories were compared to find the optimal spectrophotometric method for determining the content of flavonoids in the F. cymosum complex leaves.

\section{EXPERIMENTAL}

Spectral and absorbance measurements were carried out using A Shimadzu UV1600 spectrophotometer with $1 \mathrm{~cm}$ quartz cells. A $40 \mathrm{kHz}$ and $250 \mathrm{~W}$ ultrasound device was used for the extractive process. The $\mathrm{pH}$ of the solutions was determined using a ShangHai Hong Yi pHS-3C pH meter radiometer. All the solutions were prepared with ultra-pure water (18 $\Omega$ ) using an Aike AKJY-20 water dispenser.

Flavonoid (rutin) was commercially obtained from Henyinshengwu Co., Ltd at a stated mass fraction purity of 0.980. All the other reagents were obtained from Ruisheng Co., Ltd and were of analytical grade. 
Sample preparation: The leaves of $F$. cymosum complex were collected from the research center of Buckwheat Industry Technology at the Guizhou Normal University. The leaves were de-enzymed at $180{ }^{\circ} \mathrm{C}$ for $5 \mathrm{~s}$ after picked, then dried oven at $80{ }^{\circ} \mathrm{C}$ with consistent weight, lastly shifted through a 0.45 $\mathrm{mm}$ sieve for experiment.

Orthogonal test design: The orthogonal test with six factors (including alcohol concentration $(\mathrm{v} / \mathrm{v})$, material-liquid ratio, reaction temperature, distillation time, extraction times and ultrasonic power)and three levels was designed to screen the extraction conditions of flavonoids from $F$. cymosum complex leaves. The parameters of L18 $\left(3^{7}\right)$ orthogonal tests were shown in Table-1. Powder (dry weight, $3 \mathrm{~g}$ ) of F. cymosum complex leaves was accurately weighed and 18 experiments were conducted according to L18 $\left(3^{7}\right)$ orthogonal test table. Finally, the extract was transferred into a $50 \mathrm{~mL}$ volumetric flask, respectively. The fixed solutions were scanned by UVvisible spectrophotometer ${ }^{13}$, which is the most common method at present. Triplicates were conducted for each treatment.

Flavonoids extraction: A sample powder (3 g) was accurately weighed and placed in a $50 \mathrm{~mL}$ screw cap plastic tube with a conical bottom. The optimum extracting technology given using orthogonal experimental in this study was used to extract flavonoids and extraction were measured by four spectrophotometric methods as follows.

Method A ( $\mathrm{AlCl}_{3}-\mathrm{KAC}$ spectrophotometric method): Firstly, $1 \mathrm{~mL}$ of flavonoids extracts was accurately removed in a volumetric flask $(10 \mathrm{~mL})$ by adding $2 \mathrm{~mL}$ of the $\mathrm{AlCl}_{3}$ $(0.1 \mathrm{M})$ solution, $3.0 \mathrm{~mL}$ of $\mathrm{KAC}(1 \mathrm{M})$ solution, $4 \mathrm{~mL}$ methanol sequentially and stirred evenly, then centrifuged $10 \mathrm{~min}$ at 4000 rpm. As absorbance (A) of the samples in the 200-1000 nm was measured, so did the reagent blanks (without colour reagent, namely reagents with aluminum ions).

Method $\mathrm{B}\left(\mathrm{NaNO}_{2}-\mathrm{Al}\left(\mathrm{NO}_{3}\right)_{3}-\mathrm{NaOH}\right.$ spectrophotometric method): Firstly, $1 \mathrm{~mL}$ of flavonoids extracts was accurately removed in a volumetric flask $(10 \mathrm{~mL})$ by adding $2 \mathrm{~mL}$ of ultra-pure water and $0.5 \mathrm{~mL}$ of the $\mathrm{NaNO}_{2}(5 \%)$ solution, shaken up and then left to stand for $6 \mathrm{~min}$. Secondly, $0.5 \mathrm{~mL}$ of the $\mathrm{Al}\left(\mathrm{NO}_{3}\right)_{3}(10 \%)$ solution was added to the volumetric flask, shaken and left to stand for $6 \mathrm{~min}$. Finally, $2.5 \mathrm{~mL}$ of the $\mathrm{NaOH}(5 \%)$ solution was added to the volumetric flask, followed by addition of water to the scale, shaken and left to stand for $15 \mathrm{~min}$ before determination. The following operations were conducted as described in the procedure of method A.

Method $\mathrm{C}\left(\mathrm{NaNO}_{2}-\mathrm{AlCl}_{3}-\mathrm{NaOH}\right.$ spectrophotometric method): Firstly, $1 \mathrm{~mL}$ of flavonoids extracts was accurately removed in a volumetric flask $(10 \mathrm{~mL})$ by adding $3 \mathrm{~mL}$ of ultra-pure water and $0.3 \mathrm{~mL}$ of the $\mathrm{NaNO}_{2}(5 \%)$ solution, shaken and left to stand for $5 \mathrm{~min}$. Secondly, $0.3 \mathrm{~mL}$ of the $\mathrm{AlCl}_{3}(10 \%)$ solution was added to the volumetric flask, shaken and left to stand for $6 \mathrm{~min}$. Finally, $2.5 \mathrm{~mL}$ of the $\mathrm{NaOH}$ (1 M) solution was added to the volumetric flask, followed by addition of ultra-pure water to the scale and the following operations were conducted as described in the procedure of method A.

Method D (HAC- $\mathrm{AlCl}_{3}$ spectrophotometric method): $1 \mathrm{~mL}$ of flavonoids extracts was accurately removed in a volumetric flask $(25 \mathrm{~mL})$ by adding $4 \mathrm{~mL}$ of the ultra-pure water, $5 \mathrm{~mL}$ of the acetate buffer ( $\mathrm{pH}: 3.8$ ) solution, $3.0 \mathrm{~mL}$ of the $\mathrm{AlCl}_{3}(0.1 \mathrm{M})$ solution, followed by addition of methanol to the scale, shaken and left to stand for $0.5 \mathrm{~h}$ and the following operations were conducted as described in the procedure of method A.

Evaluate the stability of four methods: Flavonoids extraction was determined by four methods, respectively. The four absorbance $(\Delta \mathrm{A})$ values of extraction were obtained by subtracting the absorbance values of blank from the absorbance (A) values of extraction and then the data of absorbance $(\Delta \mathrm{A})$ values were processed in the descriptive statistics analysis by SPSS software to evaluate the stability of four methods in $600 \mathrm{~s}$.

Method validation: The linearity was evaluated through the construction of calibration curves, prepared on the same day, with five concentrations $(0.10,0.20,0.30,0.40$ and 0.50 $\mathrm{mg} / \mathrm{mL}$ ). The calculation of linear regression was employed by the method of least squares.

The precision was realized through five concentrations levels $(0,20,40,60$ and $80 \mathrm{mg} / \mathrm{mL})$, which were added under the same experimental conditions in the next two days and five replicates of each concentration, respectively. The accuracy was determined by the recovery test, which consists in adding known amounts of flavonoids reference substance to the samples. The precision was determined by the relative standard deviation (RSD).

\section{RESULTS AND DISCUSSION}

Optimization of the experimental condition: Table-2 showed the maximum yield ( $\%$ ) of $F$. cymosum complex leaves is 1.6568 , but the corresponding extraction condition is not necessary to be the best technology. The range analysis and variance analysis of orthogonal test results were calculated by statistical software (zhengjiaoshiyanzhushou II, http:// www.onlinedown.net/softdown/16188_2.htm). According to Table-3,Factors influenced the yield (\%) of F. cymosum complex leaves are listed in a decreasing order as follows: alcohol concentration $>$ materials-liquid ratio $>$ ultrasonic power $>$ extraction times $>$ distilled time $>$ reaction temperature according to the $\mathrm{R}$ value. According to Table-4, alcohol concentration levels took extremely significant effect to extract, but the effect of other factors is not significant. The optimal parameters are alcohol concentration $60 \%$, liquid material ratio 1:20 (w/v), ultrasonic power $70 \%(175 \mathrm{w})$, extraction

TABLE-1

FACTORS AND LEVELS FOR ORTHOGONAL TEST

\begin{tabular}{ccccccc}
\hline \multirow{2}{*}{$\begin{array}{c}\text { Variable } \\
\text { levels }\end{array}$} & \multicolumn{5}{c}{ Factors } \\
\cline { 2 - 7 } & $\begin{array}{c}\text { Alcohol } \\
\text { concentration }(\mathrm{v} / \mathrm{v})\end{array}$ & $\begin{array}{c}\text { Material-liquid } \\
\text { ratio }(\mathrm{w} / \mathrm{v})\end{array}$ & $\begin{array}{c}\text { Reaction } \\
\text { temperature }\left({ }^{\circ} \mathrm{C}\right)\end{array}$ & $\begin{array}{c}\text { Distilled } \\
\text { time }(\mathrm{min})\end{array}$ & $\begin{array}{c}\text { Extraction } \\
\text { times }\end{array}$ & $\begin{array}{c}\text { Ultrasonic } \\
\text { power }(\%)\end{array}$ \\
\hline 1 & 30 & $1: 10$ & 20 & 10 & 1 & 40 \\
2 & 60 & $1: 20$ & 40 & 20 & 2 & 70 \\
3 & 90 & $1: 30$ & 60 & 30 & 3 & 100 \\
\hline
\end{tabular}


TABLE-2

L18 $\left(3^{7}\right)$ ORTHOGONAL TEST DESIGN AND RESULTS

\begin{tabular}{|c|c|c|c|c|c|c|c|}
\hline Test No. & $\begin{array}{c}\text { Alcohol } \\
\text { concentration }(\mathrm{v} / \mathrm{v})\end{array}$ & $\begin{array}{l}\text { Material-liquid } \\
\text { ratio }(\mathrm{w} / \mathrm{v})\end{array}$ & $\begin{array}{c}\text { Reaction } \\
\text { temperature }\left({ }^{\circ} \mathrm{C}\right)\end{array}$ & $\begin{array}{l}\text { Distilled time } \\
(\mathrm{min})\end{array}$ & $\begin{array}{c}\text { Extraction } \\
\text { times }\end{array}$ & $\begin{array}{l}\text { Ultrasonic } \\
\text { power }(\%)\end{array}$ & $\begin{array}{c}\text { Extraction } \\
\text { yield }(\%)\end{array}$ \\
\hline 1 & 40 & $1: 10$ & 20 & 10 & 1 & 40 & 0.2760 \\
\hline 2 & 40 & $1: 20$ & 40 & 20 & 2 & 70 & 1.3812 \\
\hline 3 & 40 & $1: 30$ & 60 & 30 & 3 & 100 & 0.5052 \\
\hline 4 & 60 & $1: 10$ & 20 & 20 & 2 & 100 & 0.2913 \\
\hline 5 & 60 & $1: 20$ & 40 & 30 & 3 & 40 & 1.2999 \\
\hline 6 & 60 & $1: 30$ & 60 & 10 & 1 & 70 & 0.7671 \\
\hline 8 & 80 & $1: 20$ & 60 & 20 & 1 & 100 & 0.0058 \\
\hline 9 & 80 & $1: 30$ & 20 & 30 & 2 & 40 & 0.2862 \\
\hline 10 & 40 & $1: 10$ & 60 & 30 & 2 & 70 & 0.4950 \\
\hline 11 & 40 & $1: 20$ & 20 & 10 & 3 & 100 & 0.6732 \\
\hline 12 & 40 & $1: 30$ & 40 & 20 & 1 & 40 & 0.8575 \\
\hline 13 & 60 & $1: 10$ & 40 & 30 & 1 & 100 & 0.3598 \\
\hline 14 & 60 & $1: 20$ & 60 & 10 & 2 & 40 & 0.9883 \\
\hline 16 & 80 & $1: 10$ & 60 & 20 & 3 & 40 & 0.2018 \\
\hline 17 & 80 & $1: 20$ & 20 & 30 & 1 & 70 & 0.0170 \\
\hline 18 & 80 & $1: 30$ & 40 & 10 & 2 & 100 & 0.2018 \\
\hline
\end{tabular}

TABLE-3

TABLE OF RANGE ANALYSIS

\begin{tabular}{|c|c|c|c|c|c|c|}
\hline Kij & $\begin{array}{c}\text { Alcohol } \\
\text { concentration }(\mathrm{v} / \mathrm{v})\end{array}$ & $\begin{array}{l}\text { Material-liquid } \\
\text { ratio }(\mathrm{W} / \mathrm{v})\end{array}$ & $\begin{array}{c}\text { Reaction } \\
\text { temperature }\left({ }^{\circ} \mathrm{C}\right)\end{array}$ & $\begin{array}{l}\text { Distilled time } \\
(\mathrm{min})\end{array}$ & Extraction times & $\begin{array}{c}\text { Ultrasonic power } \\
(\%)\end{array}$ \\
\hline K1 & 0.698 & 0.272 & 0.533 & 0.486 & 0.381 & 0.652 \\
\hline $\mathrm{K} 2$ & 0.894 & 0.728 & 0.685 & 0.732 & 0.607 & 0.721 \\
\hline $\mathrm{K} 3$ & 0.120 & 0.712 & 0.494 & 0.494 & 0.724 & 0.340 \\
\hline $\mathrm{R}$ & 0.774 & 0.456 & 0.191 & 0.246 & 0.343 & 0.381 \\
\hline
\end{tabular}

times 3 times, distilled time $20 \mathrm{~min}$, reaction temperature $40^{\circ} \mathrm{C}$. The content of flavonoids extracted from $F$. cymosum complex leaves by the optimum extracting technology reaches to $1.817 \%$. So the optimum technology is feasible and the content of flavonoids extracted from $F$. cymosum complex leaves by the optimum extracting technology is higher.

\begin{tabular}{lcccc}
\hline \multicolumn{5}{c}{ TABLE-4 } \\
TABLE OF VARIANCE ANALYSIS \\
\hline \multicolumn{1}{c}{ Factor } & Q & DF & F & F0.01 \\
\hline Alcohol concentration & 1.941 & 2 & $14.325^{\text {a }}$ & 6.940 \\
Material - liquid ratio & 0.803 & 2 & 5.926 & 6.940 \\
Reaction temperature & 0.122 & 2 & 0.900 & 6.940 \\
Distilled time & 0.235 & 2 & 1.734 & 6.940 \\
Extraction times & 0.367 & 2 & 2.708 & 6.940 \\
Ultrasonic Power & 0.496 & 2 & 3.661 & 6.940 \\
Error & 0.270 & 4 & - & - \\
\hline${ }^{\text {a }}$ Mean of Significant at 0.01 level & & &
\end{tabular}

Orthogonal test design and data analysis method, which have the advantage of reducing test times largely, are very effective tools for choosing the optimum experimental program in most fields. Eighteen experiments were performed according to the L18 $\left(3^{7}\right)$ orthogonal test table in this work, Otherwise 2187 experiments must be taken, thus it can save a lot of work. Therefore, orthogonal test design is a highly efficient, fast and economic experimental design method.

Wavelength scanning results of four determining methods: By scanning the wavelength of four determining methods, the corresponding wavelength of the maximum absorption peak of method A, method B, method C and method D is 409.5, 480.5, 490.5 and $392.5 \mathrm{~nm}$, respectively. The wavelengths used by the different measurement methods are distinctive, so wavelength scans should be performed in studying spectrophotometry.

Stability evaluations of four determining methods: A sample after all reagents were added is generally measured in the $600 \mathrm{~s}$, so this work focuses on investigating the stability of every methods in the $10 \mathrm{~min}$. The absorbency values curves of sample and control using method D are the most stable, followed by method $\mathrm{C}$, method A and method B. The absorbance (A) values, which used to calculate flavonoids content at last, is the absorbency values of sample minus the control's. Fig. 1 and Table-5 confirm the absorbance (A) values of method $\mathrm{D}$ are the best stable, while the other three methods have more peaks and troughs. The standard error, standard deviation, variance, kurtosis and skewness of method D are all better than other three methods in the analysis, so method D is the optimal method to determine flavonoids contents in leaves of F. cymosum complex.

Buffer is very important for industrial production, scientific research and all life processes, many processes can be carried out smoothly only in a certain range of $\mathrm{pH}$ value, while a lot of experiments carried out in the buffer system, such as: Electrophoresis, HPLC, etc. The results show that flavonoids and aluminum ions in the buffer can happen a chromogenic reaction and flavonoids in the buffer can be stably measured within a longer time. Therefore, the spectrophotometric measurement process finished smoothly within a buffer system. However, whether the buffer plays a bad role needs to be studied in the future. 
TABLE-5

STATISTICAL ANALYSIS OF THE DETERMINED VALUES ABOUT FOUR METHODS

\begin{tabular}{|c|c|c|c|c|c|c|c|}
\hline Series & Standard error & $\begin{array}{l}\text { Standard } \\
\text { deviation }\end{array}$ & Variance & Kurtosis & Skewness & Data region & $\begin{array}{l}\text { Confidence } \\
\text { level }(95 \%)\end{array}$ \\
\hline 1 & 0.001438 & 0.035251 & 0.001243 & 0.901349 & -1.05592 & 0.185 & 0.002824 \\
\hline 2 & 0.014969 & 0.366962 & 0.134661 & 0.416979 & -1.27979 & 1.5739 & 0.029397 \\
\hline 3 & 0.002058 & 0.050455 & 0.002546 & -1.01038 & -0.58426 & 0.1839 & 0.004042 \\
\hline 4 & 8.89E-05 & 0.002179 & 4.75E-06 & 0.014313 & 0.682147 & 0.0106 & 0.000175 \\
\hline
\end{tabular}

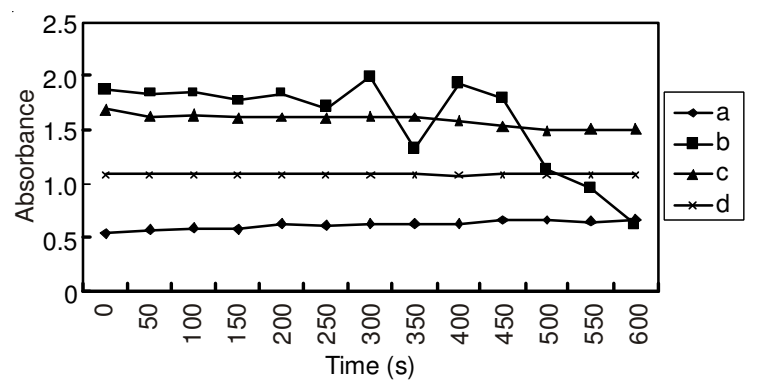

Fig. 1. Absorbance $(\Delta \mathrm{A})$ values change curves within 600 seconds; (a) method A (b) method B (c) method C (d) method D

Methodological evaluation: The linear regression equation calculated from the calibration curve is given in Table- 6 . The linear regression equation $y=0.065992 x-0.000721$, where $\mathrm{x}$ is concentration and $\mathrm{y}$ is the absorbance $(\Delta \mathrm{A})$ values. The correlation coefficient is $\mathrm{r}=0.9993$, indicating good linearity on the $0.08-1.00 \mathrm{mg} / \mathrm{mL}$ range (Fig. 2).

TABLE-6

EXPERIMENTAL OBSERVATIONS OF CALIBRATION CUIVE

\begin{tabular}{ccc}
\hline Series & Concentration $(\mathrm{mg} / \mathrm{mL})$ & Values $(\Delta \mathrm{A})$ \\
\hline 1 & 0.10 & 0.528 \\
2 & 0.20 & 1.068 \\
3 & 0.30 & 1.734 \\
4 & 0.40 & 2.358 \\
5 & 0.50 & 3.000 \\
\hline
\end{tabular}

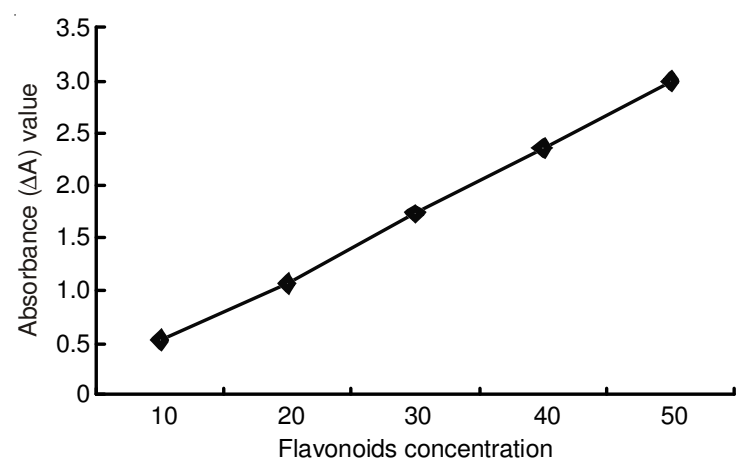

Fig. 2. Calibration curve for regressed absorbance $(\Delta \mathrm{A})$ values versus flavonoids concentration

This proposed method is applied to the recovery test. The results shown in Table-7 indicate that the recoveries are 98.04$101.02 \%$ and this method can be used for the determination of flavonoids in real samples. RSD values of the first day and the next day are satisfactory $(<2 \%)$. The results indicated that the proposed methods are precise and accurate.

\section{Conclusion}

A simple, accurate and precise spectrophotometric method for the determination of flavonoids has been successfully
TABLE-7

DETERMINATION RESULTS OF SAMPLES AND RECOVERY

\begin{tabular}{cccccc}
\hline Sample & $\begin{array}{c}\text { Flavonoids } \\
(\mathrm{added}) \\
(\mu \mathrm{g} / \mathrm{mL})\end{array}$ & $\begin{array}{c}\text { Number } \\
\text { of } \\
\text { samples }\end{array}$ & $\begin{array}{c}\text { Flavonoids } \\
(\text { found }) \\
(\mu \mathrm{g} / \mathrm{mL})\end{array}$ & $\begin{array}{c}\text { Recovery } \\
(\%)\end{array}$ & $\begin{array}{c}\text { RSD } \\
(\%)\end{array}$ \\
\hline \multicolumn{6}{c}{ Day 1 } \\
\hline 1 & - & 5 & 33.15 & - & - \\
2 & 20 & 5 & 53.34 & 100.57 & 1.50 \\
3 & 40 & 5 & 73.26 & 100.33 & 1.06 \\
4 & 60 & 5 & 92.85 & 99.10 & 0.92 \\
5 & 80 & 5 & 112.98 & 99.49 & 1.67 \\
\hline \multicolumn{7}{c}{ Day 2 } & & \\
\hline 1 & - & 5 & 33.21 & - & - \\
2 & 20 & 5 & 52.55 & 98.04 & 1.18 \\
3 & 40 & 5 & 73.54 & 101.02 & 1.44 \\
4 & 60 & 5 & 92.62 & 98.25 & 1.04 \\
5 & 80 & 5 & 112.59 & 98.16 & 1.26 \\
\hline
\end{tabular}

developed and validated. Method proposed can be applied in quality control laboratories for flavonoids analysis of real samples and it provides the certain reference to determination of flavonoids in other plants.

\section{ACKNOWLEDGEMENTS}

This work was financed by Nature Science Foundation of China (No. 31060207,31171609), the Earmarked Fund for China Agriculture Research System (CARS-08-A4), the Project of the Scientific and Technological Innovation Teams in Guizhou (QianKeHe RenCai TuanDui (2011) 4007), Guizhou Key Agricultural Project (QianKeHe NY Zi 2010 3094) and the Scientific and Technological Project in Guiyang (ZhuKeHeTong 2011102 1-12).

\section{REFERENCES}

1. J.B. Harborne and C.A. Williams, Phytochemistry, 55, 481 (2000)

2. V. Lakshmi, S.K. Joseph, S. Srivastava, S.K. Verma, M.K. Sahoo, V. Dube, S.K. Mishra and P.K. Murthy, Acta Trop., 116, 127 (2010).

3. Syamsudin, Asian J. Chem., 22, 425 (2010).

4. S.C. Fang, C.L. Hsu, H.T. Lin and G.C. Yen, J. Agric. Food Chem., 58, 814 (2010)

5. J.H. Jin, H. Lim, S.Y. Kwon, K.H. Son and H.P. Kim, Biomol. Ther, 18, 197 (2010).

6. M.F. Yam, V. Lim, I.M. Salman, O.Z. Ameer, L.F. Ang, N. Rosidah, M.F. Abdulkarim, G.Z. Abdullah, R. Basir, A. Sadikun and M.Z. Asmawi, Molecules, 15, 4452 (2010).

7. A. Jain, A.K. Singhai and V.K. Dixit, Indian J. Pharm. Sci., 68, 740 (2006).

8. E. Kokkou, G. Siasos, D. Tousoulis, E. Oikonomou, M. Kollia, S. Kioufis, M. Zaromitidou, N. Gouliopoulos, A. Verveniotis, D. Athanasiou, K. Zisimos, A.G. Papavassiliou and Ch. Stefanadis, J. Am. Coll. Cardiol., 59, E2068 (2012).

9. I. Naeem, Z. Saddiqe, A. Patel and C. Hellio, Asian J. Chem., 22, 3596 (2010).

10. J.H. Li, Q.F. Chen and F.J. Zeller, Syst. Evol., 274, 1 (2008).

11. Q.F. Chen, Bot. J. Linn. Soc., 131, 177 (1999).

12. N. Liu, F.J. Zeller and Q.F. Chen, Genet. Resour. Crop. Ev., 59, 1 (2012).

13. J.T. Lin, S. Ch. Liu, G.J. Tsay and D.J. Yang, Food Chem., 121, 659 (2010). 